\title{
Erratum to: Statistical Methods and Applications in Insurance and Finance
}

M'hamed Eddahbi, El Hassan Essaky and Josep Vives

\section{Erratum to:}

M. Eddahbi et al. (eds.), Statistical Methods and Applications

in Insurance and Finance, Springer Proceedings in Mathematics \& Statistics 158, DOI 10.1007/978-3-319-30417-5

The book was inadvertently published with an incorrect subtitle as CIMPA School, Marrakech and El Kelaa M'gouna, Morocco, April 2013. The correct subtitle is CIMPA School, Marrakech and Kelaat M'gouna, Morocco, April 2013.

The updated original online version for this book frontmatter can be found at DOI 10.1007/978-3-319-30417-5

\footnotetext{
M. Eddahbi ( $\square)$

Department of Mathematics, Université Cadi Ayyad, Marrakesh, Morocco

e-mail:m.eddahbi@uca.ma

E.H. Essaky

Faculté Polydisciplinaire de Safi, Université Cadi Ayyad, Safi, Morocco

e-mail: essaky@uca.ma

J. Vives

Faculty of Mathematics, University of Barcelona, Barcelona, Spain

e-mail: josep.vives@ub.edu 